\title{
ANALISIS EFFECT SIZE PENGARUH MODUL BERBASIS SAINSTIFIK PADA PEMBELAJARAN IPA
}

\author{
Rikizaputra ${ }^{1}$, Lufri ${ }^{2}$, Ali Amran ${ }^{3}$, Asrizal ${ }^{4}$, Hardeli $^{5}$ \\ ${ }^{1}$ Universitas Lancang Kuning Pekanbaru, Indonesia \\ $2,3,4,5$ Universitas Negeri Padang, Indonesia \\ *Corresponding Author: rikizaputra@Unilak.ac.id
}

DOI: $10.24929 /$ lensa.v11i1.161

Received: 11 April 2021

Revised: 19 April 2021

Accepted: 9 Mei 2021

\begin{abstract}
ABSTRAK
Modul IPA berbasis saintifik diperlukan dalam pembelajaran IPA karena memberikan pengaruh baik terhadap perkembangan pemikiran siswa. Tujuan dari penelitian ini adalah mengetahui effect size pengaruh modul IPA berbasis saintifik pada hasil belajar, keterampilan proses sains dan berpikir krtitis. Penelitian menggunakan metode meta analisis dengan 20 artikel sebagai subjek penelitian. Hasil penelitian menunjukkan rerata effect size pengaruh modul IPA berbasis saintifik terhadap hasil belajar yaitu 1,29 kategori tinggi, effect size pengaruhnya terhadap keterampilan proses sains 1,51 kategori tinggi, effect size pengaruhnya terhadap berpikir krtitis 1,08 kategori tinggi dan effect size pengaruh modul IPA berbasis saintifik pada siswa SMP dan SMA masing-masing 1,32 dan 1,68 kategori tinggi. Sehingga disimpulkan bahwa modul IPA berbasis saintifik menunjukkan pengaruh positif pada hasil belajar, keterampilan proses sains dan keterampilan berpikir kritis siswa dan penggunaan modul IPA berbasis saintifik lebih baik di SMA dibandingkan SMP.
\end{abstract}

Kata kunci: Modul, saintifik, pembelajaran IPA

\section{ABSTRACT}

Science module-based science are needed in science learning because they have a good influence on the development of students' thinking. The purpose of this research is to know the effect size of the effect of the science-based science module on learning outcomes, science process skills and critical thinking. This study used a meta-analysis method with 20 articles as research subjects. The results showed that the average effect size of the scientific-based science-based module on learning outcomes was 1.29 in the high category, the effect size of the effect on science process skills was 1.51 in the high category, the effect size on critical thinking was 1.08 in the high category and the effect size on the effect of the module. Sciencebased science for junior and senior high school students respectively 1.32 and 1.68 in the high category. So that it is concluded the science-based science module has a positive effect on learning outcomes, science process skills and students' critical thinking skills and the use of science-based science modules is better in high school than junior high school.

Keywords: Module, scientific, science learning

\section{PENDAHULUAN}

Pembelajaran IPA adalah suatu proses yang terjadi pada kegiatan pembelajaran yang diarahkan terbentuknya kebermaknaan dalam pembelajaran, untuk mewujudkan hal itu maka dalam pembelajaran dilakukan pengaturan sedemikian rupa sehingga benar-benar kontekstual atau terkait dunia nyata siswa, dengan demikian akan memberikan kemudahan bagi siswa mengaitkan pengetahuannya yang sudah ada dalam struktur kognitifnya dengan apa yang sedang atau baru saja dipelajarinya, hal tersebut akan memudahkan siswa dalam menemukan hubungan-hubungan antara kosep IPA sedang dan sudah dipelajarinya. Proses menemukan hubungan antar konsep IPA yang siswa lakukan dengan apa yang ada di lingkungannya dengan berbagai pengalaman yang mereka miliki akan mengarahkan mereka pada pendekatan (Rahmatiah, 2014). 
Sujarwanta (2012), pembelajaran IPA berbasis saintifik merupakan proses yang mendorong terwujudnya pengalaman langsung dengan berbagai karater siantifik dalam penerapannya seperti observasi dan ekperimen sehingga hasil pembelajaran yang diperoleh betul-betul valid dan dapat dipertanggungjawabkan. Sejalan dengan itu, Rosana (2014) menyatakan sudah menjadi hakikatnya bahwa pada setiap proses pembelajaran IPA diisyaratkan hadirnya kegiatan kegiatan yang berorientasi pada pendekatan saintifik, hal tersebut dapat dilakukan melalui rangkaian pengamatan, bertanya, menemukan hubungan, melakukan ekperimen dan berkomunikasi dengan bantuan berbagai media dan bahan ajar. dengan demikian peningkatan hasil belajar siswa berupa intelektual dan keterampilan sebagaimana yang diharapkan oleh pembelajaran abad 21 seperti berpikir kritis, kreatif, pemecahan masalah keterampilan berkomunikasi dapat terwujud melalui proses pembelajaran IPA yang dipandu oleh guru.

Pengembangan bahan pembelajaran adalah satu dari beberapa kompetensi yang perlu dikuasai pendidik dalam melaksanakan pembelajaran IPA. Hal ini penting dilakukan agar efektifitas dan efisiensi pembelajaran terwujud serta pembelajaran berjalan sesuai tujuan yang akan dicapai (Sungkono, 2003). PP NO 19 tahun 2005 Pasal 20, menghendaki agar guru memiliki kemampuan dalam proses pengembangan bahan ajar, sehingga tergambar pada pengembangan rencana pelaksanaan pembelajaran ada setiap jenjang pendidikan. Di dalam rencana pelaksanaan pembelajaran sumber belajar merupakan bagian penting yang harus ada, oleh sebab itu pengembangan sumber belajar menjadi prioritas perbaikan oleh guru.

Banyak media dalam kegiatan pembelajaran yang bisa dirancang dan dimodifikasi dalam rangka pengembangannya, salah satunya adalah modul. Modul yang digunakan sebagai sumber belajar khususnya pada pembelajaran IPA dapat membanu siswa agar konsep konsep IPA yang abstrak bisa menjadi terasa lebih konkrit dan kontekstual sehingga materi yang sedang dipelajari mudah dipahami. Modul yang meruoakan bagian dari bahan ajar atau sumber belajar yang akan digunakan tentu harus disusun dengan sistematis menggunakan bahasa dan konten berdasarkan tingkat usia pengetahuan siswa agar mudah dipahami sehingga dapat dipakai secara mandiri melalui bimbingan dan arahan. Sejauh mana hasil belajar pada konsep yang sedang mereka pelajari dapat mereka kuasai, dengan mengunakan modul dapat mereka rasakan karena kejelasan konsep yang menjadi pembahasan setiap satuan modul, jika suatu konsep materi sudah mereka kuasai maka bisa dilanjutkan pada tingkat berikutnya dan begitu juga sebaliknya (Prastowo, 2014).

Menarik atau tidaknya suatu modul bukan menjadi standar satu satunya, tetapi rasa ingin tahu terhadap materi yang akan mereka pelajari harus tumbuh setelah mengunakan suatu modeul tersebut, karena rasa ingin tahu memberikan dampak pada prestasi belajar siswa. Novelyya (2019) menemukan keingintahuan siswa yang tinggi memberikan dampak pada pencapaian hasil belajar siswa. Tingginya keingintahuan siswa pada konsep yang dipelajari akan memotivasi siswa lebih giat belajar sehingga terjadi peningkatan keterampilan berpikir tinggi dan prestasi belajar siswa. Redhana (2019), berpikir tingkat tinggi seperti berikir kritis dan keterampilan lainnya merupakan bagian penting dewasa ini yang perlu dikuasai siswa melalui proses pembelajaran yang dilaluinya. Artinya harus ada strategi yang tepat yang harus digunakan sebagaimana diantaranya yang diharapkan dari penerpan modul saintifik dalam pembelajaran.

\section{METODE PENELITIAN}

Metode yang digunakan berupa meta analisis. Denagan melakukan identifikasi, menganalisis, mengevaluasi serta menginterpretasikan semua artikel yang didokumentasikan. Peneliti melakukan review dan intentifikasi artikel secara sistematis. Ada 20 artikel dari jurnal nasional dan internasional yang dianalisis yang terkait dengan implemetasi modul ajar IPA dalam pembelajaran. Hasil analisis dan interpretasi akan dirangkum dalam pembahasan.

Data sekunder digunakan pada pada penelitian ini karena data tersebut didapatkan dari hasil-hasil penelitian yang yang pernah dilakukan peneliti-peneliti 
sebelumnya. Data dikumpulkan menggunakan teknik dokumentasi. Besarnya pengaruh suatu perlakukan dapat dilihat dari effect size (ES) dapat menggunakan rumus Glass (Glass, 1981). Rumusnya adalah:

$$
S E=\frac{\bar{x}_{\text {postest }}-\bar{x}_{\text {pretest }}}{S D_{\text {pretest }}}
$$

Atau

atau

$$
\mathrm{ES}=\frac{\sqrt{(N 1-1) S 1^{2}+(N 2-2) S 2^{2}}}{\mathrm{~N} 1+\mathrm{N} 2-2}
$$

Keterangan :

$$
S E=\mathrm{t} \sqrt{\frac{1}{n_{E}}-\frac{1}{n_{C}}}
$$

SE $\quad=$ Ukuran efek

$X_{\text {postest }}=$ Rata-rata posttest

$X_{\text {pretest }}=$ Rata-rata pretest

$S D_{\text {pretest }}=$ Standar Deviasi

$X_{E} \quad=$ Rata-rata kelompok eksperimen

$X_{C} \quad=$ Rata-rata kelompok control

$\mathrm{t} \quad=$ Nilai $\mathrm{t}$

$\mathrm{n} \quad=$ Jumlah sampel

Tabel 1 Kriteria ukuran effect size

\begin{tabular}{ccc}
\hline No & ES & Kategori \\
\hline 2 & $0,8<$ ES $<2,0$ & Tinggi \\
3 & $0,5<$ ES $<0,8$ & Sedang \\
4 & $0,1<$ ES $<1,5$ & Rendah \\
\hline
\end{tabular}

\section{HASIL DAN PEMBAHASA}

Data yang dikumulkan dianalisis, sehinga diperoleh hal-hal seperti berikut:

Modul IPA Berbasis Saintifik Berpengaruh Terhadap Hasil Belajar Siswa

Besarnya pengaruh pemgunaan modul IPA berbasis saintifik terhadap hasil belajar dapat diketahui dari effect size (ES) yang ditimbulkan. Data dimaksud disajikan pada pada tabel berikut.

Tabel 2. Rerata Effect Size Pengaruh Modul terhadap Hasil belajar IPA

\begin{tabular}{cccc}
\hline No & Kode Artikel & Effect Size & Kategori \\
\hline 1 & A1 & 0,90 & Tinggi \\
2 & A5 & 1,22 & Tinggi \\
3 & A6 & 0,95 & Tinggi \\
4 & A7 & 1,55 & Tinggi \\
5 & A8 & 1,34 & Tinggi \\
6 & A9 & 1,10 & Tinggi \\
7 & A12 & 1,23 & Tinggi \\
8 & A14 & 1,67 & Tinggi \\
9 & A15 & 1,72 & Tinggi \\
10 & A16 & 1,45 & Tinggi \\
11 & A17 & 1,54 & Tinggi \\
12 & A18 & 0,88 & Tinggi \\
\hline
\end{tabular}

Pada Tabel 2 dapat diketahui, rerata ES yaitu 1,29 kategori tingi. Angka ini menunjukkan bahwa terdapat pengaruh yang kuat penggunaan modul IPA berbasis saintifik terhadap hasil belajar IPA. Artinya penggunaan modul ini dapat memperbaiki atau meningktkan hasil belajar IPA. 
Tujuan dari proses pembelajaran salah satunya adalah agar peserta didik menguasai apa yang mereka pelajari. Tingkat keberhasilan penguasaan siswa setelah mengikuti pembelajaran merupakan indikasi dari keberhasilan dari suatu proses pembelajaran yang dilakukan. Ranah kognitif merupakan salah satu aspek hasil belajar yang menjadi sasaran pengembangan dari proses pembelajaran. Ketercapaian hasil belajar ditentukan oleh metode pembelajaran digunakan serta kemapuan guru dalam memilih media ajar yang sesuai dengan kateristik materi yang akan diajarkan.

Modul merupakan salah satu media yang perlu diimplemetasikan pada kegiatan belajar, termasuk pembelajaran IPA. Modul dalam pemebelajaran IPA perlu disesuaikan dengan karater IPA sebagai suatu ilmu yang berbasis saintifik. Modul IPA berbasis sainstifik sesuai digunakan dalam pembelajaran IPA. Hal tersebut akan membantuk siswa dalam memahami IPA sehingga memperbaiki hasil belajar mereka. Arimadona dan Silvina (2019) menemukan bahwa modul IPA berbasis saintifik pada materi zat adiktif dan psikotropikaefektif meningkatkan hasil belajar siswa. Agusti et al (2019), modul pembelajaran berbasis saintifik meningkatkan hasil belajar siswa khsusnya pada materi sistem reproduksi.

Hasil penelitian Setiyadi et al (2017) menemukan bahwa hasil belajar siswa meningkat setelah belajar biologi dengan menggunakan modul berbasis saintfik. Marera (2019), pembelajaran dengan modul biologi berbasis saintifk dapat meningkatkan hasil belajar siswa. Sejalan dengan itu Yani et al (2019) menemukan bahwa pengembangan modul berbasis santifik efektif memperbaiki proses dan meningkatkan hasil belajar pada kosep Plantae. Sukiminiandari (2015) menyatakan bahwa penerapan modul ajar berbasis saintifik sesuai ddigunakan dalam pembelajaran IPA fisika.

Alwi (2018) menemukan bahwa modul IPA berbasis saintifik efektif digunakan pada pembelajarn. Sejalan dengan itu, Yerimadesi et al (2016) menyatakan modul kesetimbangan kimia berbasis saintifik efektif meningkatkankan hasil tes kognitif siswa. Asmiyunda et al (2018) menemukan modul elektronik berbasis saintifik dapat meningkatkan tes hasil belajar siswa. Saputra dan Advinda (2018) juga menemukan bahwa modul biologi yang dikembangkan efektif meningkatkan prestasi belajar siswa.

Modul IPA berbasis saintifik yang digunanakan dalam pembelajaran selain bisa meningkatkan hasil belajar kognitif, juga bisa membantu meningkatkan aspek afektif dan keterampilan siswa. Hasil Penelitian Kliyanti et al (2018) menunjukkan bahwa pengembangan modul keanekaragaman hayati berbasis pendekatan saintifik dapat membantu siswa belajar secara mandiri. Sejalan dengan itu, Satria et al (2017) menemukan bahwa modul biologi yang dikembangkan secara saintifik dapat meningkatkan kemampuan afektif siswa. Astuti et al (2016), peningkatan prestasi belajar kimia pada ranah pengetahuan, afektif dan keterampilan terlihat setelah siswa belajar dengan modul berbasis scientifik. Artinya adanya efektifitas pembelajaran yang terjadi.

\section{Sains Siswa \\ Pengaruh Modul IPA Berbasis Saintifik Terhadap Keterampilan Proses}

Pengaruh penggunaan modul IPA berbasis saintifi terhadap keterampilan proses sains siswa dapat dilihat pada tabel 3 berikut.

Tabel 3. Rerata Effect Size Pengaruh Modul terhadap Keterampilan Proses Saiins

\begin{tabular}{cccc}
\hline No & Kode Artikel & Effect Size & Kategori \\
\hline 1 & $\mathrm{~A} 2$ & 1,45 & Tinggi \\
2 & $\mathrm{~A} 10$ & 1,23 & Tinggi \\
3 & $\mathrm{~A} 11$ & 1,64 & Tinggi \\
4 & $\mathrm{~A} 18$ & 1,72 & Tinggi \\
\hline & Kategori & 1,51 & Tinggi
\end{tabular}

Berdasarkan Tabel 3 dapat diketahui bahwa penggunaan modul IPA berbasis saintifik berpengaruh terhadap keterampilan rposes siswa. Pengaruh tersebut dapat ditunjukkan oleh ES yang mencapai 1,51 pada kategori tinggi. Ini menunjukkan adanya efektifitas keterampilan proses sains siswa dalam belajar jika menggunakan modul ini. 
Keterampilan proses sains menrupakan satu komepentensi penting yang harus dimiliki siswa dalam memahmi IPA baik biologi, fisika maupun kimia. Karena IPA bukan hanya suatu produk yang cukup diketahui saja, tetapi IPA juga proses yang mesti dipahami dan dilakukan. Ketrampilan proses sains menakankan pada berpikir proses bukan konsep. Media yang digunakan dalam proses pembelajaran IPA akan mempengaruhi tingkat perkembangan keterampilan proses siswa. Syafi'ah dan Laili (2020) menemukan bahwa kegiatan pembelajaran IPA yang dilakukan siswa dengan berbasis pendekatan saintifik mampu melatih keterampilan proses IPA siswa.

Modul salah satu media yang dapat mempengaruhi keterampilan proses sais siswa. Modul pembelajaran IPA yang berbasis saintifik sangat penting digunakan karena saintifk merupakan karater utama dari proses penyelidikan IPA. Sumiati et al (2018) menemukan pengaruh yang besar dari modul berbasis saintifik terhadap peningkatan keterampilan proses sains siswa pada pembelajaran fisika. Sejalan dengan itu Kirana et al (2018) menemukan bahwa keterampilan proses sains siswa mengalami peningkatan setelah siswa belajar melalui modul fisika berbasis saintifik.

\section{Pengaruh Modul IPA Berbasis Saintifik Terhadap Berpikir Kritis}

Pengaruh penggunaan modul IPA berbasis saintifik terhadap keerampilan berpikir kritis siswa dapat dilihat pada tabel 4 berikut.

Tabel 4 Rerata Effect Size Pengaruh Modul terhadap Keterampilan Berpikir Kritis

\begin{tabular}{cccc}
\hline No & Kode Artikel & Effect Size & Kategori \\
\hline 1 & $\mathrm{~A} 3$ & 0,86 & Tinggi \\
2 & $\mathrm{~A} 13$ & 1,14 & Tinggi \\
3 & $\mathrm{~A} 19$ & 1,12 & Tinggi \\
4 & $\mathrm{~A} 20$ & 1,22 & Tinggi \\
\hline & Kategori & 1,08 & Tinggi \\
\hline
\end{tabular}

Berdasarkan Tabel 4 dapat diketahui bahwa penggunaan modul IPA berbasis saintifik berpengaruh terhadap keterampilan berpikir kritis siswa. Pengaruh tersebut dapat ditunjukkan oleh ES yang mencapai 1,08 pada kategori tinggi. Ini menunjukkan adanya efektifitas keterampilan proses sains siswa dalam belajar jika menggunakan modul ini.

Keterampilan berpikir tingkat tinggi (higher order thinking skill) menjadi kompetensi utama hari ini yang harus dikuasai siswa, hal tersebut disebabkann berbagai masalah kompleks yang harus dihadapi memasuki persaingan abad 21 ini. Oleh sebab itu pembelajaran di sekolah juga diarakan pada pembelajaran yang mampu melatih keteramilan berpikir tingkat tinggi siswa.

Berbagai keterampilan yang digolongkan para ahli kedalam berpikir tingkat tinggi diataranya berpikir kritis, analitis, kreatif dan problem solving. Disamping cara yang digunakan dalam pembelajaran tepat, media pembelajaran yang digunakan dalam pembelajaran IPA juga harus diperhatikan agar cocok dengan karater IPA dan tujuan keterampilan berpikir tingkat tinggi yang ingin dicapai.

Pendekatan saintifik harus dipadukan pada modul IPA agar membiasakan siswa untuk berpikir lebih dalam melalui proses bepikir sehingga akan melatih cara berpikir mereka lebih mendalam seingga terbentuk kterampilan berpikir tingkat tinggi mereka. Dewi et al (2019) menemukan, modul IPA berbasis saintifik efektif digunakan pada pembelajaran IPA yang ditandai dengan peningkatan kemampuan berpikir kritis siswa. Sejalan dengan itu, Rasyidi (2020) menyatakan bahwa pembelajaran dengan modul terpadu saintifik dapat meningkatkan berpikir kritis siswa. Wakhidah (2018) menemukan bahwa ada perbedaan berpikir kritis pembelajar antara kelas yang menggunakan pendekatan saintifik dengan pembelajaran konvesional.

Hasil penelitian Natalina et al (2016) menemukan bahwa modul IPA biologi berbasis saintifik berdampak pada peningkatan keterampilan berpikir kritis siswa. Sejalan dengan itu Prawita (2019) menyatakan bahwa modul biologi berbasis pemebelajaran generatif efektif diterapkan dalam rangka meningkatkan keterampilan berpikir analitis siswa. Pembelajaran generatif merupakan pembelajaran yang 
berorientasi pada konstruktivisme, sedangkan konstruktivisme adalah pendekatan yang bersifat saintifik.

\section{Pengaruh Modul IPA Berbasis Saintifik Ditinjau Tingkat Pendidikan}

Modul IPA berbasis saintifik yang dimplementasikan di sekolah memberikan pengaruh atau dampak yang berbeda pada level sekolah yang diteliti, walaupun pengaruh tersebut masih sama-sama pada kategori tinggi, selengkapnya sebagaimana pada tabel 5 berikut:

Tabel 5. Rerata Pengaruh Modul Saintifik Ditinjau Dari Jenjang Pendidikan

\begin{tabular}{ccccc}
\hline No & Jenjang & Kode & Effect Size & Kategori \\
\hline 1 & SMP & A1, A2, A5, A6, A7, A12, A14, A, 16, A19 & 1,32 & Tinggi \\
2 & SMA & $\begin{array}{c}\text { A3, A8, A9, A10, A11, A12, A13, A15, A17, } \\
\text { A18, A20 }\end{array}$ & 1,68 & Tinggi \\
\hline
\end{tabular}

Pada Tabel 5 dapat diketahui bahwa penggunaan modul IPA berbasis saintifik memberikan dampak atau pengaruh yang lebih tinggi pada jenjang SMA bila dibandingkan dengan jenjang SMP. Rerata ES pada jenajng SMP 1,32 sedangkan jenjang SMA 1,68. Ini menujukkan bserapan siswa terhadap pembelajaran melalui modul saintifik pada SMA lebih efektif bila dibandingkan dengan SMP, tetapi secara kategori baik pada SMP atau SMA berada pada kategori tinggi. Savitri et al (2017) menyatakan modul yang dikembangkan sesuai digunaka pada siswa. Perbedaan anatara siswa SMP dan SMA Ini bisa disebabkan oleh faktor umur dan pengalaman. Marera (2019) menemukan bahwa penerapan modul biologi berbasis saintifik efektif digunakan pada pembelajaran SMA.

Umur mempengaruhi kreativitas anak. Keingintahuan, iamjinasi dan kemandirian, semakin memberikan resiko terhadap penguatan komtmen dalam menyelesaikan tugas yang diberikan. Kematangan usia berbanding lurus dengan kemandirian, menjalankan resiko dan menjalankan komitmen tugas. Umur juga berpengaruh pada kreativitas anak, menggambar dan kepribadian. Menurut Allport yang di kutip dalam Djaali (2008) mengungkapkan bahwa sikap merupakan bagian kesiapan mental kognitif dan syaraf yang terbentuk melalui pengalaman serta berpengaruh pada tanggapan seseorang terhadap segala sesuatu dan situasi yang berhubungan dengan objek. Dengan adanya pengalaman belajar yang berbeda-beda maka siswa akan mempunyai sikap yang berbeda-beda pula dalam pembelajaran. Menurut Wiliam Burton dalam Hamalik (2013) bahwa pengalaman belajar meliputi adanya perubahan perilaku seperti keberanian untuk bertanya keberanian untuk berpendapat selain perubahan perilaku, ada juga perubahan nilai, seperti perubahan karater atau nilai, tanggung jawab serta keserasian dalam melakoni kehidupan.

\section{KESIMPULAN}

Berdasarkan analisis yang dilakukan, dapat disimpulkan bahwa modul pembejaran IPA berbasis saintifik berpengaruh terhadap hasil belajar dengan rerata effect size 1,29, keterampilan proses sians siswa dengan rerata effect size 1,51 dan keterampilan berpikir kritis siswa dengan rerata effect size 1,08 . Pengaruh modul pada pembelajaran IPA siswa SMA lebih baik daripada siswa SMP dengan rerata effect size masing-masing 1,32 dan 1,68.

\section{SARAN}

Untuk penelitian berikutnya perlu dilakukan analisis terhadap artikel yang lebih banyak lagi pada topik sejenis terutama pada jurnal nasional terakreditasi dan jurnal internasional untuk mendapatkan hasil yang lebih mendalam. 


\section{DAFTAR PUSTAKA}

Arimadona S \& Silvina R. (2019). Pengembangan Modul Pembelajaran Zat Adiktif Dan Psikotropika Berbasis Scientific Approach Dengan Crossword Puzzle. Jipva (Jurnal Pendidikan IPA Veteran). Volume 3 - Nomor 1, 2019.

Agusti D., Rahmatan H., Sulastri. (2019). Pengembangan Modul Pembelajaran Sistem Reproduksi Berazaskan Al-Quran/Hadis Untuk Meningkatkan motivasi Dan Hasil Belajar Peserta Didik. EDUSAINS, 11(1), 2019, 132-140.

Alwi A.M. (2018). Pengembangan Modul Berbasis Pendekatan Saintifik Pada Mata Pelajaran IPA Di SMP. Jurnal Teknologi Pendidikan dan Pembelajaran Tahun 5, Nomor 1 Juli 2018.

Astuti D.R.,Saputro S., Mulyani S. (2016). Pengembangan Modul Kimia Berbasis Scientific Approach Pada Materi Ikatan Kimia Kelas X SMA/MA Semester 1. JURNAL INKUIRI ISSN: 2252-7893, Vol 5, No. 2, 2016 (hal 71-78).

Asmiyunda.,Guspatni.,Azra F. (2018). (Pengembangan E-Modul Keseimbangan Kimia Berbasis Pendekatan Saintifik Untuk Kelas XI SMA/MA. JEP Volume 2 Nomor 2 November 2018.

Dewi I.S. ,Sunarno W.,Dwiastuti S. (2019). Pengembangan Modul IPA Berbasis Saintifik Pada Materi Interaksi Mahluk Hidup Dengan Lingkungan Untuk Meningkatkan Kemampuan Berpikir Kritis Dan Hasil Belajar Siswa Kelas VII SMP. INKUIRI: Jurnal Pendidikan IPA Vol. 8, No. 2, 2019 (hal 186-197).

Glass, G.V., McGaw B., \& Smith, M.L. 1981. Meta-Analysis in Social Research. Sage Publications. London: Sage Publications.

Djaali. (2008). Psikologi Pendidikan. Jakarta: PT Bumi Aksara.

Hamalik, O. (2013). Proses Belajar Mengajar. Jakarta: PT Bumi Aksara.

Kirana F.C., A. Hali.,Rahwanto (2018). Pengembangan dan Implementasi Modul Fisika Berbasis Saintifik pada Materi Alat Optik untuk Meningkatkan KPS Siswa di SMA Negeri 5 Banda Aceh. Jurnal Pendidikan Sains Indonesia (Indonesian Journal of Science Education), Vol. 06, No. 02, hlm 107-111, 2018.

Kliyanti S.M.,Nengsih R.,Yulianti E. (2018). Pengembangan Modul Keanekaragaman Hayati Berbasis Pendekatan Saintifik Untuk Siswa Kelas X SMA/MA Sederajat . Biocolony Vol. 1 No. 2, Desember 2018. Hal: 34-39.

Marera A. (2019). Development Of Biology Learning Module Based On Scientific Approach On Respiratory System Topic In Senior High School. Jurnal Al-Ahya Volume 1 Nomor 3 Oktober 2019.

Natalina M.,Syafi'i.,W.,Heryen S. (2016). Pengembangan Modul Pembelajaran IPA Biologi Berorientasi Pendekatan Saintifik Untuk Meningkatkan Kemampuan Berpikir Kritis Pada Materi Struktur Tumbuhan. Jurnal Biogenesis Vol. 13 (1): $141-148,2016$.

Novelyya, S. (2019). Pengaruh Karakter Rasa Ingin Tahu Siswa Terhadap Hasil Belajar Mata Pelajaran Ipa Fisika Di Smp Negeri 08 Muaro Jambi. BRILIANT Jurnal Riset dan Konseptual. Volume 4 Nomor 2

Prawita W.,Prayitno B.A.,, Sugiyarto. (2019). Effectiveness of a Generative LearningBased Biology Module to Improve the Analytical Thinking Skills of the Students 
with High and Low Reading Motivation. International Journal of Instruction. January 2019 . Vol.12, No.1.

Prastowo, A. (2014). Pengembangan Bahan Ajar Tematik Tinjauan Teoritis dan Praktik. Jakarta. Kencana Prenadamedia Group.Purwanto. 2011. Evaluasi Hasil Belajar. Yogyakarta: Pustaka Pelajar.

Rahmatiah. (2014). Mengasah Kreativitas dengan IPA Terpadu. Sulawesi Selatan: Artikel EBuletin LPMP Sulsel ISSN 2355- 3189.

Rasyidi M. (2020). Pengembangan Modul IPA Terpadu Saintifik Learning Terhadap Peningkatkan Kemampuan Berpikir Kritis Dan Hasil Belajar Siswa Kelas VII Mts Sabilurrosyad Barabali. Intelektiva : Jurnal Ekonomi, Sosial \& Humaniora Vol.01 No. 12.

Redhana, I.W,.(2019). Mengembangkan Keterampilan Abad Ke-21 Dalam Pembelajaran Kimia. Jurnal Inovasi Pendidikan Kimia, Vol 13, No 1

Sapitri D., Ardi.,Leilani I. (2017). Pengembangan Modul Berbasis Pendekatan Saintifik Disertai Glosarium Tentang Materi Sistem Ekskresi Pada Manusia Untuk Peserta Didik Kelas VIII. Journal Biosains Volume 1 Nomor 22017.

Saputra A.,Advinda L. (2018). Development of Biology Learning Module Nuanced Quran in Learning Material of Coordination System for Islamic Senior High School Students. International Journal of Progressive Sciences and Technologies (IJPSAT) Vol. 11 No. 1 October 2018, pp. 55-60.

Satria A.A., Juhri AM., Achyani. (2017). Pengembangan Modul Biologi Berbasis Saintifik Terintegrasi Al-Qur'an Dan Hadist Terhadap Afektif Siswa Sma Negeri Tiga Dihaji Oku Selatan. Jurnal Lentera Pendidikan Pusat Penelitian LPPM UM METRO Vol. 2. No. 2, Desember 2017.

Setiyadi M.W., Ismail.,Gani A.H.(2017). Pengembangan Modul Pembelajaran Biologi Berbasis Pendekatan Saintifik Untuk Meningkatkan Hasil Belajar Siswa. Journal of Educational Science and Technology Volume 3 Nomor 2 Agustus $2017 \mathrm{Hal}$. 102- 112.

Sujarwanta A. (2012). Mengkondisikan Pembelajaran IPA dengan Pendekatan Saintifik. Jurnal Nuansa Kependidikan. Vol 16 Nomor.1, Nopember 2012. Halaman 75-83.

Sukiminiandari Y.P.,Budi A.S.,Supriyati Y. (2015). Pengembangan Modul Pembelajaran Fisika Denganpendekatan Saintifik. Prosiding Seminar Nasional Fisika (E-Journal) SNF2015 http://snf-unj.ac.id/kumpulan-prosiding/snf2015/ VOLUME IV, OKTOBER 2015.

Sumiati E.,Septian D.,F. Faizah. (2018).Pengembangan Modul Fisika Berbasis Scientific Approach Untuk Meningkatkan Keterampilan Proses Sains Siswa. Jurnal Pendidikan Fisika dan Keilmuan (JPFK), 4 (2), 2018, 75-88.

Sungkono.(2003). Pengembangan dan Pemanfaatan Bahan Ajar Modul Dalam Pembelajaran. Yogyakarta: Universitas Negeri Yogyakarta.

Syafi'ah, R. \& Laili, A.M. (2020). Pengembangan LKS IPA SMP Kelas VII Berbasis Pendekatan Saintifik Untuk Melatihkan Keterampilan Proses IPA Siswa. Lensa (Lentera Sains): Jurnal Pendidikan IPA Volume 10 Nomor 2 
Wakhidah, N. (2018). Pembelajaran Dengan Pendekatan Saintifik Terhadap Kemampuan Berpikir Kritis Mahasiswa Calon Guru Madrasah Ibtidaiyah. Premiere Educandum: Jurnal Pendidikan Dasar dan Pembelajaran 8(2) 2018

Yani A.,Tahmir S., Muhiddin. (2019). Developing Scientific Approach Based Learning Module In Plantae Concept. ResearchGate

Yerimadesi.,Bayharti.,Handayani F., \& Legi W.F. (2016). Pengembangan Modul Kesetimbangan Kimia Berbasis Pendekatan Saintifik Untuk Kelas XI SMA/MA. Journal of Sainstek. ISSN:2085-8019. Published by Association of Mathematics Science Education and Technology State Institute of Islamic Studies (AMSETIAIN) Batusangkar. 